\title{
DECOLOURATION KINETICS OF CHLOROPHYLLS AND CAROTENOIDS IN VIRGIN OLIVE OIL BY AUTOXIDATION.
}

Ramón Aparicio-Ruiz ${ }^{\mathrm{a}}$ and Beatriz Gandul-Rojas ${ }^{\mathrm{b}}$.

${ }^{a}$ Analytical Chemistry Department, Faculty of Pharmacy (University of Seville). C/ Profesor García González, 2. 41012 Seville, Spain.

${ }^{b}$ Chemistry and Biochemistry Pigment Group, Department of Food Phytochemistry.

Instituto de la Grasa (CSIC), Av. Padre García Tejero, 4, 41012 Seville, Spain.

*Corresponding author: gandul@ cica.es.

*Corresponding author telephone: $\quad 34-954691054$

$$
\text { telefax: } \quad 34-954691262
$$

e-mail addresses of all authors: aparicioruiz@cica.es, gandul@ cica.es 


\section{ABSTRACT}

2 Kinetic models are capable of predicting shelf life in keeping with the different variables that can

3 affect the degradation of the food item. In this work, virgin olive oils (VOOs) extracted from

4 olive fruits at three ripening stages with high, medium and low pigment content respectively,

5 were thermodegraded to characterize the kinetic and thermodynamic parameters for the

6 oxidation of two pigment fractions: a green fraction (chlorophylls) and a yellow fraction

7 (carotenoids). A first-order kinetic mechanism was appropriate for describing the decolouration

8 processes under non-oxygen thermal auto-oxidation. A marked effect of temperature has been

9 pointed out, with the carotenoids (CARs) being the most affected by heat. The kinetic constants

10 for the CARs degradation were about 3.6 times higher than the respective for chlorophylls

11 (CHLs) that showed a more stable structure to decolouration by heat. As well, higher activation

12 energy of CHLs $\left(16.03 \pm 0.26 \mathrm{kcal} \cdot \mathrm{mol}^{-1}\right)$ as compared to CARs $\left(15.45 \pm 0.17 \mathrm{kcal} \cdot \mathrm{mol}^{-1}\right)$ implies

13 that a smaller temperature change is needed to increase the kinetic constant of CHLs.

14 Neither isokinetic ratio and nor compensation existed between the three VOO matrixes and

15 further, for each pigment fraction (CHLs or CARs) all kinetic constants were explained by a

16 single Arrhenius line. Consequently, the differences between the oily matrices did not

17 significantly affect the decolouration mechanisms, and moreover, the kinetic parameters

18 obtained as temperature functions according to Arrhenius model, can be used to develop a

19 prediction mathematical model for decolouration of CHL and CAR pigment fractions in VOO

20 over time and depending on temperature.

22 Keywords: Virgin olive oil; chlorophyll; carotenoid; thermodegradation; kinetic; Arrhenius 23 parameters. 


\section{Introduction}

Each technological process for obtaining and/or storage of vegetable foods is associated with a specific transformation of their carotenoid and chlorophyll pigments. This fact makes these functional constituents appropriate as quality indicators for final product quality. And also demonstrate their potential applicability as a tool for process traceability.

Virgin olive oil (VOO) is known for its high levels of monounsaturated fatty acids that help maintain normal blood cholesterol levels (Commission Regulation EU, 2012). It is also a good source of phytochemicals including polyphenolic compounds, squalene, alpha-tocopherol, and carotenoids and chlorophylls which have health benefits that include reduction of risk factor of coronary heart disease, prevention of several varieties of cancers, modification of immune and inflammatory responses and antioxidant activity (García-González, Aparicio-Ruiz \& Aparicio, 2008; Lercker \& Caramia, 2010). A nutrition claim for olive oil polyphenols have been recently authorized (EFSA, 2011; Commission Regulation EU, 2012).

Chlorophyll and carotenoid pigments are highly appreciated as functional components both for its colouring properties as its health benefits for the human consumption. Carotenoids, besides their participation in yellow colouring of fruits, vegetables and oils, are bioactive compounds which have provitamin A function ( $\beta$-carotene and $\beta$-cryptoxanthin), antioxidant activity, and prevent age-related macular degeneration and cataract formation (lutein) (Seddon et al., 1994). Also, it has been demonstrated, in both in vitro and in vivo animal model assays, that the chlorophyll compounds, in addition to its function as green colouring, exhibit a series of biological properties, such as antioxidant and antimutagenic activities, modulation of xenobiotic enzyme activity, and induction of apoptotic events in cancer cell lines, all consistent with the prevention of degenerative diseases (Ferruzzi \& Blakeslee, 2007).

The importance of the biological properties of chlorophylls and carotenoids together with the potential of those compounds in the determination of quality and authenticity of a VOO leads 
to the importance of tracking the degradation of those compounds during the storage or heat treatment in order to know the loss of biological properties of VOO and possible conditions of the olive oil before marketing. Carotenoids and chlorophylls are widely affected by heat treatment, while the first undergoing reactions of trans-cis isomerization and rearrangements of 5,6-epoxide groups to 5,8-furanoxide groups in vegetable foods thermally processed (MínguezMosquera \& Jarén-Galán, 1999; Pérez-Gávez, Jarén-Galán, \& Mínguez-Mosquera, 2000; Shi \& Le Maguer, 2000; Sanchez, Carmona, Ordoudi, Tsimidou \& Alonso, 2008, Zhao, Kim, Pan, \& Chung (2014), and the seconds by decarbomethoxilation and allomerization in C-13 ${ }^{2}$ of the isocyclic ring of the chlorophylls (Mínguez-Mosquera, Gandul-Rojas, Gallardo-Guerrero, Roca \& Jarén-Galán, 2007). Under a powerful processed, both pigment fractions undergo autooxidation with the destruction of chromophore groups (Aman, Schieber \& Carle, 2005; Schwartz \& Lorenzo, 1990). All these reactions can modify the functional properties of these compounds and/or alter their bioavailability.

Lutein and $\beta$-carotene are the major carotenoids in virgin olive oil (VOO) but also believed other xantophylls as neoxanthin, violaxanthin, anteraxanthin and $\beta$-crytoxanthin. Pheophytin $a$ and $b$ are the major chlorophyll pigments in VOO followed by chlorophyll $a$ and $b$, OH-pheophytin $a$ and $b$ and lactone-pheophytin $a$ and $b$ (Gandul-Rojas \& Mínguez-Mosquera, 1996)

Kinetic models are capable of predicting shelf life in keeping with the different variables that can affect the degradation of the food item. Numerous experimental works describe VOOs degradation, but until recently the kinetic performance in oxidation parameters (ManceboCampos, Fregapane \& Salvador, 2008; Farhoosh \& Hoseini-Yazdi, 2014) and individual pigment thermodegradation products have not been reported (Aparicio-Ruiz, Mínguez-Mosquera \& Gandul-Rojas, 2010; Aparicio-Ruiz, Mínguez-Mosquera \& Gandul-Rojas, 2011; AparicioRuiz \& Gandul-Rojas, 2012). 
This research work is aimed at the kinetic study and characterization of the thermodynamic parameters governing the thermal degradation reactions of two pigment fractions: green fraction (chlorophylls) and yellow fraction (carotenoids) in VOO, to advance in the knowledge of the thermal stability of these pigment fractions in an oily matrix, and for the first time to establish mathematical models enabling the prediction of the behavior of its decolouration reactions by autoxidation versus thermal variables governing critic points in storage and/or processing of this food e.g. soft deodorization or cooking/frying.

\section{Materials and methods}

\subsection{Chemicals and standards.}

Tetrabutylammonium acetate and ammonium acetate were supplied by Fluka (Zwijndrecht, TheNetherlands). HPLC reagent grade solvents were purchased from Teknokroma (Barcelona, Spain), and analytical grade solvents were supplied by Panreac (Barcelona, Spain). For the preparation, isolation, and purification of chlorophyll pigments, analytical grade reagents were used (Panreac). The deionized water used was obtained from a Milli-Q 50 system (Millipore Corp., Bedford, MA). Standards of chlorophyll $a / b$ (chl $a / b$ ) was supplied by Sigma-Aldrich Co. Standards of pheophytin $a / b$ (phy $a / b$ ) and pyropheophytin $a / b$ (pyphy $a / b$ ) were provided by Wako Chemicals Gmbh (Neuss, Germany). The C-13 epimer of phy $a / b$ was prepared by treatment with chloroform according to the method of Watanabe et al. (1984). $13^{2}$-OH-phy a/b was obtained by selenium dioxide oxidation of phy $a / b$ at reflux heating for $4 \mathrm{~h}$ in pyridine solution under argon (Hynninen, 1991). $15^{1}-\mathrm{OH}-$ lactone-phy $a / b$ was obtained from phy $a / b$ by alkaline oxidation in aqueous media according to the method of Mínguez-Mosquera \& GandulRojas (1995).

Reference samples of lutein, $\beta$-carotene, neoxanthin, violaxanthin and antheraxanthin were obtained from a pigment extract of fresh spinach saponified with $3.5 \mathrm{M} \mathrm{KOH}$ in methanol 
and isolated by TLC on silica gel GF254 (0.7 mm thickness) on 20 x $20 \mathrm{~cm}$ plates using petroleum ether $\left(65-95^{\circ} \mathrm{C}\right) /$ acetone/diethylamine (10:4:1, v/v/v) (Mínguez-Mosquera, GandulRojas \& Gallardo-Guerrero, 1992). Luteoxanthin, auroxanthin, neochrome, and mutatoxanthin were obtained by acidification with $1 \mathrm{M} \mathrm{HCl}$ in ethanol (Khachik, Beecher \& Whittaker 1986). $\beta$-cryptoxanthin was obtained from red peppers (Mínguez-Mosquera \& Hornero-Méndez, 1993). All standards were purified by TLC using different eluents (Mínguez-Mosquera et al. 2007).

\subsection{Samples.}

The study of thermal degradation of pigments was carried out with virgin olive oils obtained by physical extraction into a two-phase system (Di Giovanchino, 2013) and supplied by a single industrial mill (Cooperativa Sor Ángela de la Cruz, Estepa, Seville) to avoid any effect of pedoclimatic and agricultural parameters and the industrial variables of the extraction systems in the comparative studies. In order to have three lots of oil with a differing pigment content, the starting material used was a mixture of two oil variety olives - Hojiblanca and Manzanilla picked in three different months: November (sample N), December (sample D), and January (sample J). The proportion of fruits between varieties was 20/80, 80/20 and 100/0 respectively. The dates of picking correspond to high, medium, and low pigment levels (referring to the green colour) and correlated inversely with the degree of fruit ripening according to the method of Walalí-Loudiyi, Chimitah, Loussert, Mahhou \& Boulouha (1984).

\subsection{Heat treatment.}

Preliminary assays, with a commercial sample of VOO, enabled an approximate determination of the degree of conversion for the main reactions to be studied (Aparicio-Ruiz et al. 2010 and 2011; Aparicio-Ruiz \& Gandul-Rojas, 2012) and established a range of times for an appropriate sampling at each temperature. The total time of each experiment changed depending on the assay temperature: $42 \mathrm{~h}\left(120^{\circ} \mathrm{C}\right), 64 \mathrm{~h}\left(100^{\circ} \mathrm{C}\right), 370 \mathrm{~h}\left(80^{\circ} \mathrm{C}\right)$ and $744 \mathrm{~h}\left(60^{\circ} \mathrm{C}\right)$. At least 128 aliquots (32 for each of the four assay temperatures) were separated from each oil lot (samples N, D, and 
$124 \mathrm{~J}$ ). These aliquots were put into glass tubes that were sealed in the absence of air and placed in

125 thermostatted ovens at the temperatures fixed for each experiment. These four temperatures were

126 used to determine the kinetic and thermodynamic parameters (reaction order, reaction rate, and 127 activation energies).

$128 \quad$ For each oil lot, two samples were analysed for each time/temperature pair. The samples 129 were removed from the thermostatted ovens at fixed time intervals, depending on each 130 experiment, to obtain a total of at least 16 duplicate samples. The samples were cooled rapidly in 131 an ice bath and then kept at $-20^{\circ} \mathrm{C}$ until analysis of the pigments.

$132 \quad 2.4$ Extraction and analysis of chlorophyll and carotenoid pigments.

133 All procedures were performed under green lighting to avoid any photooxidation reactions. Pigment 134 extraction was performed by liquid-phase distribution. This method was developed for virgin 135 olive oil by Mínguez-Mosquera, Gandul-Rojas, Garrido-Fernández \& Gallardo-Guerrero (1990). 136 The technique is based on the selective separation of components between $\mathrm{N}, \mathrm{N}$ 137 dimethylformamide (DMF) and hexane. The oil sample (10-15g) was dissolved directly in $138150 \mathrm{~mL}$ of DMF and treated with five $50 \mathrm{~mL}$ successive portions of hexane in a decanting funnel. 139 The hexane phase carried over lipids and carotene fraction while the DMF phase retained 140 chlorophyll pigments and xanthophylls. This system yielded a concentrated pigment solution that 141 was oil free and could be adequately analyzed by chromatographic techniques. HPLC analysis of chlorophyll pigments was performed according to a modification of the

143 method of Mínguez-Mosquera et al. (1992), as is described by Roca, Gallardo-Guerrero, 144 Minguez-Mosquera \& Gandul-Rojas (2010). A reverse phased column (20 cm x $0.46 \mathrm{~cm})$ packed 145 with $3 \mu \mathrm{m} \mathrm{C18} \mathrm{Spherisorb} \mathrm{ODS2} \mathrm{(Teknokroma,} \mathrm{Barcelona,} \mathrm{Spain)} \mathrm{and} \mathrm{an} \mathrm{elution} \mathrm{gradient} \mathrm{with}$ 146 the solvents (A) water/ion-pair reagent/methanol $(1: 1: 8, \mathrm{v} / \mathrm{v} / \mathrm{v})$ and $(\mathrm{B})$ acetone/methanol $(1: 1$ $147 \mathrm{v} / \mathrm{v})$, at a flow rate of $1.25 \mathrm{~mL} / \mathrm{min}$ were used. The ion-pair reagent was $0.05 \mathrm{M}$ 148 tetrabutylammonium acetate and $1 \mathrm{M}$ ammonium acetate in water. The pigments were identified 
149 by co-chromatography with the corresponding standard and from their spectral characteristics

150 described in detail in previous papers (Mínguez-Mosquera et al. 1992). The online UV-vis 151 spectra were recorded from 350 to $800 \mathrm{~nm}$ with the photodiode array detector. Pigments were 152 quantified at the wavelength of maximum absorption (430 nm for phyb, $13^{2}$-OH-phy $b$, pyphy $b$, 153 neoxanthin, neochrome, violaxanthin, mutatoxanthin, auroxanthin, and mutatoxanthin; $450 \mathrm{~nm}$ 154 for antheraxanthin, lutein, 9-cis-lutein, 13-cis-lutein, $\beta$-carotene (also $\beta$-carotene was directly 155 quantified in hexane phase by absorbance measurement at $450 \mathrm{~nm}), \beta$-cryptoxanthin, and chl $b$; $156410 \mathrm{~nm}$ for phya, $13^{2}-\mathrm{OH}-\mathrm{phy} a$, and pyphya; $400 \mathrm{~nm}$ for $15^{1}$-OH-lactone-phya) and were 157 quantified from the corresponding calibrate curves (amount versus integrated peak area). The 158 calibration equations were obtained by least-squares linear regression analysis over a 159 concentration range according to the levels of these pigments in VOO. Injections in duplicate 160 were made for five different volumes at each standard solution (range of concentrations 3$161700 \mathrm{ng} ; \mathrm{R}^{2}<0.9983$ ). Limit of detection (LOD) and limit of quantification (LOQ) defined at a 162 signal-to-noise ratio of about 3 and 10 respectively were $\mathrm{LOD} \leq 0.60 \mathrm{ng}$ and $\mathrm{LOQ} \leq 2 \mathrm{ng}$.

\subsection{Kinetic parameters.}

164 Changes in experimental data of total pigment concentration in the fractions of chlorophyll 165 compounds and carotenoids, expressed in $\mu \mathrm{mol} / \mathrm{kg}$, were used to calculate kinetic parameters by 166 least-squares non-linear regression analysis. The reaction order (n) and rate constant (k) were 167 determined by trial and error using the integral method: a reaction order is initially assumed in 168 the rate equation and then is integrated to obtain a mathematical expression that relates pigment 169 concentration $(\mathrm{C})$ with time $(\mathrm{t})$. The mathematical expression that best fits the changes in the 170 experimental data with the reaction time was selected to verify the order (assumed ad initio) and 171 used to obtain the rate constant $(\mathrm{k})$.

172 2.6 Thermodynamic Parameters. 
173 The effect of temperature on the rate constant was evaluated by means of the Arrhenius equation

174 with a simple reparameterization (Van Boekel, 2008) by using a reference temperature $T_{\text {ref: }}$ :

$$
k=k_{r e f} \times \exp \left[\frac{-E_{a}}{R}\left(\frac{1}{T}-\frac{1}{T_{r e f}}\right)\right]
$$

Where $R$ is the molar gas constant $\left(1.98 \mathrm{cal} \mathrm{mol}^{-1} \mathrm{~K}^{-1}\right), T$ is the absolute temperature $(\mathrm{K}), E_{a}$ is

177 the activation energy ( $\left.\mathrm{cal} \mathrm{mol}^{-1}\right), k$ is the specific reaction rate constant at the temperature $T$, and $178 k_{\text {ref }}$ is the specific reaction rate constant at the reference temperature $T_{\text {ref. }}$ The reference 179 temperature should preferably be chosen in the middle of the studied temperature regimen. were determined by the Eyring equation:

$$
\ln (k / T)=\frac{-\Delta H^{\#}}{R T}+\frac{\Delta S^{\#}}{R}+\ln \left(\frac{k_{b}}{h}\right)
$$

where $k$ is the rate constant at temperature $T, k_{\mathrm{b}}$ is the Boltzmann constant; $R$ is the molar gas constant and $h$ is the Planck constant.

Therefore, $\Delta H^{\#}$ and $\Delta S^{\#}$ were estimated on the basis of linear regression analysis of $\ln$ $\left(\mathrm{k}_{\mathrm{i}} / \mathrm{T}_{\mathrm{ij}}\right)$ versus $1 / \mathrm{T}_{\mathrm{ij}}$. The Gibbs free energy was estimated according to the Gibbs equation:

$$
\Delta G^{\#}=\Delta H^{\#}-T \Delta S^{\#}
$$

The pairs of $\Delta H^{\#}$ and $\Delta S^{\#}$ obtained were linearly correlated using the last equation. From

191 which the isokinetic temperature $\left(T_{\text {isok }}\right)$ and its corresponding Gibbs free energy $\left(\Delta \mathrm{G}_{\text {isok }}\right)$ for the reaction could be estimated 
195 Estimated parameters were expressed as means \pm SE or SD and were analyzed for differences

196 between means using one-way analysis of variance (ANOVA). Brown \& Forsythe test (Brown \&

197 Forsythe, 1974) was used as a post hoc comparison of statistical significance ( $p$ values $<0.05)$.

198 Least squares and non linear regression analysis were performed using Statistica 8.0 (StatSoft, 199 Inc., 2007) and Statgraphics Centurion XV for Windows (Statpoint Technologies, Inc., 2005).

\section{Results and discussion}

\subsection{Kinetic study.}

Table 1 shows the initial content of the pigment fractions analyzed in this study for the high $(\mathrm{N})$,

204 medium (D), and low (J) pigmentation VOO matrixes employed. The qualitative pigments 205 profile was that typical of a virgin olive oil (Gandul-Rojas, Roca \& Mínguez-Mosquera, 2000; 206 Gandul-Rojas \& Mínguez-Mosquera, 1996). In the carotenoid fraction with lutein and $\beta$-carotene 207 as majority pigments followed by violaxanthin, luteoxanthin, auroxanthin, neoxanthin, 208 antheraxanthin, mutatoxanthin and $\beta$-cryptoxanthin as minority xanthophylls, and in the 209 chlorophyll fraction with pheophytin $a$ and $b$ as major pigments, and chlorophyll $a$ and $b$, OH210 pheophytin $a$ and $b$, lactone-chlorophyll $b$, OH-chlorophyll $b$ as minor chlorophyll compounds. 211 Therefore, the values showed in Table 1 are the sum of the individual quantification of each 212 pigment corresponding to the same fraction.

In accord with the results of quantitative changes in both pigment fractions, the reaction 214 mechanisms proposed for thermal decolouration of chlorophyll pigment fraction (CHL) and 215 carotenoid pigment fraction (CAR) are shown in Figure 1.

216 The corresponding kinetic equations for the reactions show in Figure 1 are:

$$
\mathrm{V}_{\text {TotalChlorophyls }}=-\frac{\mathrm{d}[\mathrm{A}]}{\mathrm{dt}}=\mathrm{k}_{1}[\mathrm{~A}]^{\mathrm{n}}=\mathrm{V}_{\text {Total Colourless of Chlorophyls }}=\frac{2 \mathrm{q}[\mathrm{B}]}{\mathrm{dt}}
$$


$\mathrm{V}_{\text {Total Carotenoids }}=-\frac{\mathrm{d}\left[\mathrm{A}^{\prime}\right]}{\mathrm{dt}}=\mathrm{k}_{2}\left[\mathrm{~A}^{\prime}\right]^{\mathrm{n}}=\mathrm{V}_{\text {Total Colourless of Carotenoids }}=\frac{\mathrm{d}\left[\mathrm{B}^{\prime}\right]}{2}$

220

where $[A]$ is the concentration of total chlorophylls, $\left[A^{\prime}\right]$ the concentration of total carotenoids, $[B]$ and $[B]$ the concentration of noncoloured products (nc) for each reactions respectively, $k_{1}$ and $k_{2}$ are rate constants for the respective reactions, and $n$ is the reaction order.

Solving the kinetic mechanism, assuming an order of $1(n=1)$ and that all reactions are irreversible, we get

$$
[A]=[A]_{0} e^{-k_{1} \cdot t}
$$

$$
\left[A^{\prime}\right]=\left[A^{\prime}\right]_{0} e^{-k_{2} \cdot t}
$$

where $[A]_{0}$ and $\left[A^{\prime}\right]_{0}$ are the initial concentrations of CHL fraction and CAR fraction respectively.

From the proposed kinetic equations and by non-linear regression analysis of the experimental data, the rate constants for each of the proposed reactions in the mechanism were estimated. Figures 2 exemplifies, for the treatment at $120^{\circ} \mathrm{C}$ of the high-pigmentation matrix (sample $\mathrm{N}$ ), the concentration changes found and the regressions estimated for the decolouration reactions in CHL and CAR fractions.

Table 2 shows the values for the estimated rate constants, together with the standard error and determination coefficient $\left(R^{2}\right)$ for each reaction studied. The determination coefficients obtained showed a good fit of the experimental data to the equations proposed and demonstrate that the first-order mechanism is appropriate for describing the thermal decolouration of the CHL and CAR fractions in the VOO.

The relationship between the two rate constants (CHLs vs. CARs) determined that, on average, the rates of degradation of CAR fraction are 3.6 times higher than those calculated for the CHL fraction. It has been observed in some other particular cases, significant differences 
between the rate constants obtained for the various samples tested (N, D, J) (Table 2). Is the case, for example, of CHLs in the three experiments (N, D, J) at $120^{\circ} \mathrm{C}$.

The relationships between the rate constants give us an idea of the decolouration speed as

245 long as the initial concentrations are the same. In general, and according to Gandul et al. (2000), 246 the concentrations ratio between CHL and CAR fractions remained around the unit after 247 extraction of virgin olive oil at the initial season of production; this is CHLs/CARs $=0.94$ in 248 sample N. Therefore, the rate of CAR fraction degradation is in any case higher than CHL 249 fraction degradation. However, the concentrations ratio of CHLs/CARs decrease during the 250 season of production of VOO being 0.55 and 0.29 for samples D and J respectively. Therefore the decolouration speed difference between those fractions is even higher as long as it reaches 252 the end of the milling season.

From the point of view of loss of pigment during the experience of thermal degradation it was observed losses of CHLs ranging from 15 to $30 \%$ for the four temperatures used (60 to $120^{\circ} \mathrm{C}$ ), while in CARs losses are more pronounced, it ranging between 44 and $74 \%$. From the average of the four temperatures used the chlorophylls losses are around $24 \%$, while carotenoids nearly tripled reaching a $60 \%$. Older studies reported similar results being the CAR fraction with 258 a higher loss than CHL fraction, such as the decolouration test using rancimat method at $100^{\circ} \mathrm{C}$ where the pigment loss calculated for oxidized oils was $67 \%$ for the carotenoid index and $58 \%$ 260 for the chlorophyll index (Ceballos, Moyano, Vicario, Alba \& Heredia, 2003). Also, an 261 autoxidation study of the stability of VOO reported a $20 \%$ and $10 \%$ of loss of carotenoids and 262 chlorophylls to noncoloured products respectively (Psomiadou, \& Tsimidou, 2001).

Furthermore, it is obvious that the CHLs/CARs ratio data increased from its initial state, 264 since carotenoids decolouration was more pronounced than chlorophylls during 265 thermodegradation. For example, sample $\mathrm{N}$ at $120^{\circ} \mathrm{C}$ started with a CHLs/CARs ratio of 0.94 266 and reached a 1.4 value after 18 hours of heat treatment. The last data is the maximum value 
obtained for the CHLs/CARs ratio of Spanish VOO (Gandul-Rojas et al. 2000). Thus, this ratio could lead us to a good parameter as a marker of the fraudulent heat treatment of VOOs, in addition to those that we have proposed in previous paper as \% phyropheophytin a (AparicioRuiz, Roca \& Gandul-Rojas, 2012), (E) / (Z) lutein isomers ratio (Aparicio-Ruiz et al. 2011) and neoxanthin / neochrome ratio (Aparicio-Ruiz \& Gandul-Rojas, 2012).

It also shows that, in both pigment fractions, the kinetic constant increased with temperature of the experiment, regardless of the total pigment content of the samples studied (N, D, J). From the mean values calculated from the rate constants (Table 2), it was evident that there was no overlap between these constants at different temperatures studied.

\subsection{Thermodynamic study.}

Thermodynamic analysis using total concentrations of chlorophyll and carotenoid pigments will reveal which pigment fraction exhibits greater reactivity.

Table 3 displays the values estimated for the thermodynamic parameters (entropy, enthalpy, activation energy, and Gibbs free energy), with their respective standards errors for each matrix and reaction analyzed.

The thermodynamic parameters of the decolouration reaction of the CAR fraction did not show significant differences $(\mathrm{p} \leq 0.05)$, except for sample $\mathrm{N}$ in enthalpy, entropy and activation energy. However, in the case of CHL fraction, the thermodynamic parameters did not show significant differences $(\mathrm{p} \leq 0.05)$, except for sample $\mathrm{D}$ (t-test $\mathrm{p} \leq 0.05)$ in parameters such as enthalpy, entropy and activation energy.

Finally, the mean value of the thermodynamic parameters corresponding to the three oil matrixes $(\mathrm{N}, \mathrm{D}, \mathrm{J})$ for $\mathrm{CHL}$ and CAR fractions did not show significant differences ( $\mathrm{t}$-test $\mathrm{p} \leq$ 0.05) in any of its parameters except for the activation energy (Ea) that has slightly higher value in CHL than CAR fraction. This difference indicates that the chlorophylls are less reactive (and 
more stable) than the carotenoid pigments studied as a total fraction but a smaller temperature

292 change is needed to increase the kinetic constant of CHL fraction.

In all cases, values for the $T \Delta S^{\#}$ term were negative (due to the negative values of

294 entrophy); however, enthalpy values $\left(\Delta H^{\#}\right)$ were positive, as were the Gibbs free energy values

$295\left(\Delta G^{\#}\right)$, making the reactions nonspontaneous.

2963.3 Isokinetic ratio.

297 The isokinetic ratio was studied along the same lines as previous studies (Aparicio-Ruiz et al. 298 2010; Aparicio-Ruiz et al. 2011; Aparicio-Ruiz \& Gandul-Rojas, 2012), where the degradation 299 of chlorophyll and carotenoid pigments, studied individually, have not, in general (except for $300 \quad 13^{2}-\mathrm{OH}$-pheophytin $a$ and $b$ ), an isokinetic relationship between the oily matrixes studied, so, no 301 isokinetic temperature exist.

302 Therefore, it is possible to study the existence of an isokinetic relationship and 303 temperature between oily matrixes when considering the total concentration of chlorophyll and 304 carotenoid pigments.

Figures $3 \mathbf{A}$ and $3 \mathbf{B}$ show the lines of the Arrhenius equation obtained for each of the oily samples in a temperature range of 250 to $1000 \mathrm{~K}$, for CAR and CHL fractions, respectively. We could not conclude that there was an isokinetic ratio for decolouration reaction in 308 CAR fraction as the Arrhenius straight lines for the three samples (N, D, and J) did not present 309 any common cutoff points (Figure 3A). These straight lines were almost parallel, but were also 310 very close to one another (all points lie within the same interval of confidence). They are, 311 therefore, isoenthalpic and isoentropic straight lines. This observation is consistent with the 312 thermodynamic parameters (Table 3), which did not show significant differences $(t$ test $P \leq$ 313 0.05) between the various oily matrixes, except for sample N. Consequently, the CAR fraction 314 degradation to colourless products was not affected by the type of oily matrix. 
In the case of CHL fraction decolouration (Figure 3B), samples $\mathrm{N}$ and $\mathrm{J}$ had almost

316 parallel straight lines and very close one to another, while the D straight line showed slightly

317 deviation to lines $\mathrm{N}$ and $\mathrm{J}$ and cut off those lines within the temperature range studied, $336.5 \mathrm{~K}$

$318\left(63.5^{\circ} \mathrm{C}\right)$. However, the confidence limits of the line $\mathrm{J}$ included the corresponding Arrhenius

319 straight lines of the others (Samples N and D), and consequently, all the experimental points

320 were within the three confidence limits. Regarding thermodynamic parameters, as also indicated

321 in the section on thermodynamic study, samples $\mathrm{N}$ and $\mathrm{J}$ did not show significant differences $(t$

322 test $P \leq 0.05$ ) between them, but they did with the sample D, except for $\Delta G^{\#}{ }_{298}$. Similarly to the

323 case of CAR fraction, degradation of CHL fraction to colourless products was not affected by the

324 type of VOO matrix.

From this point, it is interesting to compare the two groups of fractions (CHLs vs.

326 CARs), and see how they behave. Figure 3C shows the Arrhenius lines from average value of the kinetic constants obtained in the three VOO matrixes for CAR and CHL fractions. These lines cut at temperatures above $1000 \mathrm{~K}$, and those lines can be considered as parallel inside the study interval $\left(60{ }^{\circ} \mathrm{C}\right.$ to $\left.120{ }^{\circ} \mathrm{C}\right)$, as well as isoenthalpic lines. Accordingly, these reactions are classified as distinct or separate reactions groups which have different degradation mechanisms.

331 Likewise, differences were appreciated in the degradation rates, which were higher in the carotenoid pigments than in the chlorophylls.

\subsection{Compensation effect.}

334 Liu \& Guo (2001) have demonstrated that the compensation effect and the isokinetic effect are

335 not necessarily synonymous. A kinetically compensated system requires that the different

336 thermodynamic parameters obtained for the same reaction in different environments define an 337 isokinetic line. This theoretical line includes all of the different kinetic and thermodynamic 338 coordinates of a single reaction: with the isokinetic temperature $\left(T_{\text {iso }}\right)$ being the line slope and the 339 increase in Gibbs free energy of all reactions at the $T_{\text {iso }}$ the intercept, according to: 
Errors are inevitable in experiments and the data used are therefore estimators of the corresponding variables. Consequently, it is possible that the real values are not correlated,

343 although their estimators are. This would be the case in the so-called false compensation effect.

344 Krug, Hunter \& Grieger (1976) propose that the straight line in the plane $\Delta H$ versus $\Delta S$ is only a 345 manifestation of the statistical pattern of the compensation, and this hypothesis can be ruled out 346 if the estimation of the line slope is sufficiently different from the harmonic temperature $\left(T_{\mathrm{hm}}\right)$, 347 defined as:

$$
T_{h m}=\frac{n}{\sum_{i=1}^{n} \frac{1}{T_{i}}}
$$

Liu \& Guo (2001) have proposed a method for distinguishing the real compensation effects from the false ones, based on a graphical representation of the experimental values of enthalpies and entropies with their error bars in the plane $\Delta H^{\#}$ versus $\Delta S^{\#}$.

To apply this study to our experimental data the linear regressions $\mathrm{A} H^{\#}$ versus $\mathrm{A} S^{\#}$ has been estimated for each of the reactions. Table 4 shows the values obtained for the slope $T_{\text {iso }}$ and the corresponding determination coefficients $\left(R^{2}\right)$. It can be observed a good correlation coefficients $\left(R^{2} \geq 0.99\right)$ in the total degradation of CHL and CAR fractions. This indicated the existence of a compensation effect between $\mathrm{A} H^{\#}$ and $\mathrm{A} S^{\#}$. However, from the comparison between the estimated isokinetic temperature $\left(T_{\text {iso }}\right)$ and the $T_{\mathrm{hm}}$ under the study conditions (362 $\mathrm{K})$ it is deduced that this compensation effect can be real only for the degradation of CHL fraction, where the differences between the temperatures were significant. Finally, application of 360 the method of error-bars proposed by Liu \& Guo (2001) showed that none of the reactions was a 361 real compensation effect (Figure 4).

The analysis of the thermo-degradation of CHL and CAR fractions to colourless products 363 in virgin olive oil has established a marked effect of temperature on the reaction mechanisms, 
where the CAR fraction was the most affected by heat in absence of oxygen and light. Neither

365 isokinetic and nor compensation effect have been found in both fractions of pigments.

\section{Conclusions.}

The kinetic constants for the CAR pigment fraction degradation were about 3.6 times higher than the respective for CHL pigment fraction that showed a more stable structure to decolouration by heat. As well, higher activation energy of CHLs $\left(16.03 \pm 0.26 \mathrm{kcal} \cdot \mathrm{mol}^{-1}\right)$ as compared to CARs $\left(15.45 \pm 0.17 \mathrm{kcal} \cdot \mathrm{mol}^{-1}\right)$ implies that a smaller temperature change is needed to increase the kinetic constant of CHLs. Consequently, the oily medium did not significantly affect the decolouration mechanisms, and moreover, the kinetic parameters obtained as temperature functions according to Arrhenius model, can be used to develop a prediction mathematical model for CHL and CAR fractions decolouration in VOO over time and depending on temperature in absence of oxygen and light. Neither isokinetic and nor compensation effect have been found in both fractions of pigments.

Kinetic models are becoming more popular for studying the changes in the chemical composition of food because are capable of predicting shelf life of them. For the first time in an oily food matrix as virgin olive oil, the thermal decolouration of chlorophyll and carotenoid pigment fractions by autoxidation has been studied and this kinetic model provides the producer and/or wholesaler and / or consumer with a tool to predict the behavior of these phytochemical fractions to thermal variables governing critic points in processing and storage of this food. This approach could be also used for the kinetic study of loss in relation to other important phytochemicals in virgin olive oils as polyphenols which are subject to a nutrition claim authorized for this food. We encourage the scientific community to conduct studies in this aim.

\section{Acknowledgment}

We thank Sergio Alcañiz-García for his technical assistance. 
This work was supported by the Comision Interministerial de Ciencia y Tecnología (CICYT-EU,

389 Spanish and European Governments) under research project AGL 2012-39714/ALI and by the Junta de Andalucía in the Project AGR 2010-6271 and through financial support to group AGR 148-2012. We thank Cooperativa Sor Ángela de la Cruz (Estepa, Sevilla) for supplying oil samples. Authors are members of the IBERCAROT Network, funded by CYTED (ref. 393 112RT0445).

\section{References}

395 Aman, R., Schieber, A. \& Carle, R. (2005). Effects of Heating and Illumination on Trans-Cis 396 Isomerization and Degradation of $\hat{a}$-Carotene and Lutein in Isolated Spinach Chloroplasts. $397 \quad$ Journal of Agricultural and Food Chemistry 53, 9512-9518.

398 Aparicio-Ruiz, R. \& Gandul-Rojas B. (2012). Thermal degradation kinetics of neoxanthin, 399 violaxanthin, and antheraxanthin in virgin olive oils. Journal of Agricultural and Food $400 \quad$ Chemistry, 60, 5180-5195.

401 Aparicio-Ruiz, R., Mínguez-Mosquera. M.I. \& Gandul-Rojas, B. (2010). Thermal degradation 402 kinetics of chlorophyll pigments in virgin olive oils. 1. Compounds of series a. Journal of 403 Agricultural and Food Chemistry, 58, 6200-6208.

404 Aparicio-Ruiz, R., Mínguez-Mosquera, M.I. \& Gandul-Rojas, B. (2011). Thermal degradation 405 kinetics of lutein, $\beta$-carotene and $\beta$-cryptoxanthin in virgin olive oils. Journal of Food 406 Composition and Analysis, 24, 811-820.

407 Aparicio-Ruiz R., Roca, M. \& Gandul-Rojas, B. (2012). Mathematical model to predict 408 formation of pyroheophytin $a$ in virgin olive oil during the storage. Journal of Agricultural 409 and Food Chemistry, 60, 7040-7049.

410 Brown, M.B. \& Forsythe, A.B. (1974). Robust tests for the equality of variances. Journal of the $411 \quad$ American Statistical Association, 69, 364-367. 
412 Ceballos, C., Moyano, M.J., Vicario, I.M., Alba, J. \& Heredia, F.J. (2003). Chromatic evolution 413 of virgin olive oils submitted to an accelerated oxidation. Journal of the American Oil $414 \quad$ Chemists Society, 80, 257-262.

415 Commission Regulation (EU) (2012). No 432/2012/CE. Official Journal of the European Union, $416 \quad$ L Series, (May 16), L136, 1-40.

417 Di Giovanchino. Technological Aspects: In Handbook of Olive Oil: Analysis and Properties 2nd 418 edition. Aparicio, R., Harwood J., Eds.; Springer Science: New York; 2013, pp. 57-96.

419 EFSA (2011). Scientific Opinion on the substantiation of health claims related to polyphenols in 420 olive and protection of LDL particles from oxidative damage. European Food Safety $421 \quad$ Authority Journal 9(4): 2033, 1-25.

422 Farhoosh, R. \& Hoseini-Yazdi, S-Z (2014). Evolution of Oxidative Values during Kinetic 423 studies on olive oil oxidation in the rancimat test. Journal of the American Oil Chemists Society, 91, 281-293.

Ferruzzi, M. G. \& Blakeslee, J. (2007). Digestion, absorption, and cancer preventive activity of dietary chlorophyll derivatives. Nutrition Research (N.Y.), 27, 1-12.

Gandul-Rojas, B. \& Mínguez-Mosquera, M.I. (1996). Chlorophyll and carotenoid composition in virgin olive oils from various spanish olive varieties. Journal of the Science of Food and Agriculture, 72, 31-39.

Gandul-Rojas, B., Roca-L.Cepero, M. \& Mínguez-Mosquera, M.I. (2000). Use of chlorophyll and carotenoid pigment composition to determine authenticity of virgin olive oil. Journal of the American Oil Chemists Society, 77, 853-858.

433 García-González, D.L., Aparicio-Ruiz, R. \& Aparicio, R. (2008). Virgin olive oil - Chemical 434 implications on quality and health. European Journal of Lipid Science and Technology, 110, 435 602-607. 
Hynninen, P.H. (1991). Chlorophylls. In Scheer, H. (Ed.), Chemistry of chlorophyll modifications (pp. 145-210). Boca Raton, FL: CRC Press.

438 Khachik, F., Beecher, G. R. \& Whittaker, N.F. (1986). Separation, identification, and quantification of the major carotenoid and chlorophyll constituents in extracts of several green vegetables by liquid chromatography. Journal of Agricultural and Food Chemistry, 34, 603-616.

Krug, R.R., Hunter, W.G. \& Grieger, R.A. (1976). Enthalpy-entropy compensation: 1. Some fundamental statistical problems associated with the analysis of Van't Hoff and Arrenhius data. 2. Separation of the chemical from the statistical effect. Journal of Physical Chemistry, $80,2335-2351$.

Lercker, G. \& Caramia, G.M. (2010). Chemical composition and healthy aspects of virgin olive oils (Composizione ed aspetti salutistici dell'olio d'oliva). Rivista Italiana delle Sostanze Grasse, 87, 147-169.

Liu, L. \& Guo, Q.X. (2001). Isokinetic Relationship, Isoequilibrium Relationship, and Enthalpy-Entropy Compensation. Chemical Reviews, 101, 673-695.

Mancebo-Campos, V., Fregapane, G. \& Salvador, M.D. (2008). Kinetic study for the development of an accelerated oxidative stability test to estimate virgin olive oil potential shelf life. European Journal of Lipid Science and Technology, 110, 969-976.

Mínguez-Mosquera, M. I. \& Hornero-Méndez, D. (1993). Separation and quantification of the

Mínguez-Mosquera, M. I., \& Gandul-Rojas, B. (1995). High-performance liquid 458 chromatographic study of alkaline treatment of chlorophyll. Journal of Chromatography A, 690, 161-176. 
Mínguez-Mosquera, M.I. \& Jarén-Galán M. (1999). Quantitative and qualitative changes associated with heat treatments in the carotenoid content of paprika oleoresins. Journal of Agricultural and Food Chemistry, 47, 4379-4383.

Mínguez-Mosquera, M.I., Gandul-Rojas, B. \& Gallardo-Guerrero, L. (1992). Rapid method of quantification of chlorophylls and carotenoids in virgin olive oil by HPLC. Journal of Agricultural and Food Chemistry, 40, 60-63.

Mínguez-Mosquera, M.I., Gandul-Rojas, B., Gallardo-Guerrero, M.L., Roca, M. \& Jarén-Galán, M. (2007). Chlorophylls. In Hurst, W.J. (Ed.), Methods of analysis in funtional foods and added nutraceuticals, 2nd edition (pp 337-400). Boca Raton, FL, CRC Press LLC.

Mínguez-Mosquera, M.I.; Gandul-Rojas, B.; Garrido-Fernández, J. \& Gallardo Guerrero, L. (1990). Pigment presence in virgin olive oil. Journal of the American Oil Chemists Society, 67, 192-196.

Pérez-Gávez A., Jarén-Galán, M. \& Mínguez-Mosquera, M.I. (2000). Effect of high-temperature degradative processes on ketocarotenoids present in paprika oleoresins. Journal of Agricultural and Food Chemistry, 48, 2966-2971.

Psomiadou, E. \& Tsimidou, M. (2001). Stability of virgin olive oil. 1. Autooxidation studies. Journal of Agricultural and Food Chemistry, 81, 640-647.

Roca, M., Gallardo-Guerrero, M.L., Mínguez-Mosquera, M.I. \& Gandul-Rojas, B. (2010). Control of Olive Oil Adulteration with Copper-Chlorophyll Derivatives. Journal of Agricultural and Food Chemistry, 58, 51-56.

\section{0}

Sanchez A.M., Carmona M., Ordoudi S.A., Tsimidou M.Z. \& Alonso G.L. (2008). Kinetics of individual crocetin ester degradation in aqueous extracts of saffron (Crocus sativus L.) upon thermal treatment in the dark. Journal of Agricultural and Food Chemistry, 56, 1627-1637.

Seddon, J.M., Ajani, U.A., Sperduto, R.D., Hiller, R., Blair, N., Burton, T.C., Farber, M.D., 
carotenoids, vitamin-A, vitamin-C, and vitamin-E, and advanced age-related macular degeneration. Journal of the American Medical Association, 272, 1413-1420.

487 Shi J. \& Le Maguer M. (2000). Lycopene in tomatoes: chemical and physical properties affected by food processing. Critical Reviews in Food Science and Nutrition, 40, 1-42.

489 Schwartz, S. J., \& Lorenzo, T. V. (1990). Chlorophylls in foods. Critical Reviews in Food Science and Nutrition, 29, 1-17.

491 Van Boekel, M.A.J.S. (2008). Kinetic Modeling of Food Quality: A Critical Review. 492 Comprehensive Reviews in Food Science and Food Safety, 7, 144-158.

493 Walalí-Loudiyi, D., Chimitah, M., Loussert, R., Mahhou, A. \& Boulouha, B. (1984). 494 Morphologic and physiologic characters of olive chlones from Picholine Marroqui variety. 495 Olivae, 3, 26-31.

496 Watanabe, T., Hongu, A., Honda, K., Nakazato, M., Konno, M. \& Saithoh, S. (1984). 497 Preparation of chlorophylls and pheophytins by isocratic liquid chromatography. Analytical 498 Chemistry, 56, 251-256. 
Table 1. Initial content of carotenoid and chlorophyll compounds in virgin olive oils ${ }^{a}$.

\begin{tabular}{cccc}
\hline Sample $^{b}$ & $\begin{array}{c}\text { Carotenoid } \\
\text { fraction }\end{array}$ & $\begin{array}{c}\text { Chlorophyll } \\
\text { fraction }\end{array}$ & $\begin{array}{c}\text { Total } \\
\text { pigments }^{\mathbf{c}}\end{array}$ \\
\hline $\mathbf{N}$ & $18.99 \pm 0.36$ & $17.93 \pm 0.19$ & $36.91 \pm 0.55$ \\
$\mathbf{D}$ & $18.21 \pm 0.49$ & $10.02 \pm 0.31$ & $28.23 \pm 0.80$ \\
$\mathbf{J}$ & $11.86 \pm 0.16$ & $3.44 \pm 0.10$ & $15.30 \pm 0.26$ \\
\hline
\end{tabular}

${ }^{a}$ Data, expressed as $\mu \mathrm{mol} / \mathrm{kg}$, represent mean values $\pm \mathrm{SD}$ for three determinations. $\mathrm{CV} \leq 2.8 \%$. ${ }^{b}$ The sample codex corresponds to the harvesting date of the olive fruits used to obtain the virgin olive oils studied, November (N), December (D), January (J). 'Total of chlorophyll and carotenoid pigments. 
Table 2. Rate constants $(k)$ and determination coefficients $\left(R^{2}\right)$ estimated for the kinetic mechanism of the thermal decolouration of chlorophyll and carotenoid pigment fractions in virgin olive oil ${ }^{a}$.

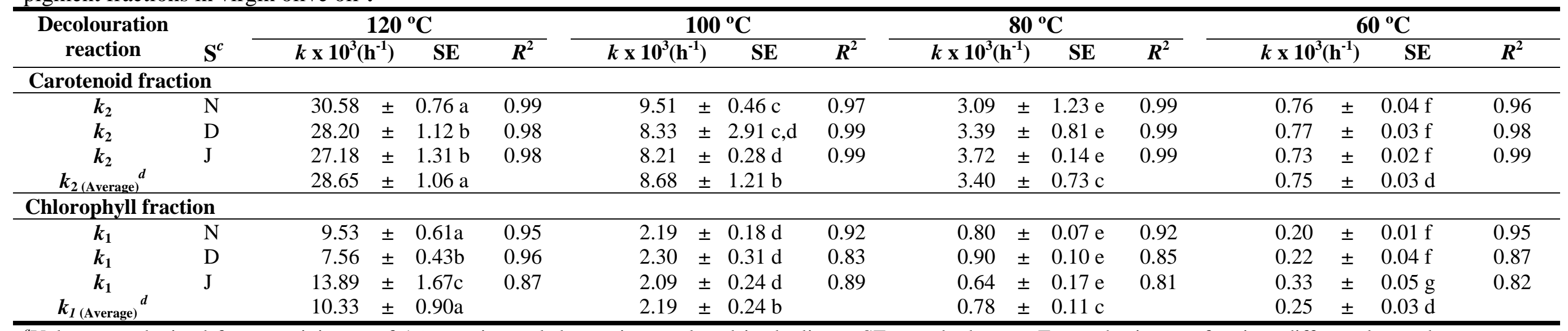

${ }^{a}$ Values are obtained from a minimum of 16 experimental data points analyzed in duplicate, SE, standard error; For each pigment fraction, different letters between rows indicate significant differences ( $\mathrm{p} \leq 0.05) ;{ }^{b}$ Reactions according to the kinetic mechanism showed in Figure $1 ;{ }^{c} \mathrm{~S}$, Sample codex as in Table $1 ;{ }^{d}$ Average values of the three samples $(\mathrm{N}, \mathrm{D}, \mathrm{J})$. 
Table 3. Thermodynamic parameters for the thermal decolouration reaction of chlorophyll and carotenoid pigment fractions in Virgin Olive Oil ${ }^{a}$.

\begin{tabular}{|c|c|c|c|c|c|}
\hline $\begin{array}{c}\text { Decolouration } \\
\text { reaction }^{b}\end{array}$ & $\mathbf{S}^{c}$ & $\begin{array}{c}\Delta S^{\#} \pm \mathrm{SE}^{d} \\
{[\mathrm{cal} /(\mathbf{m o l} \times \mathbf{K})]} \\
\end{array}$ & $\begin{array}{c}\Delta H^{\#} \pm \mathrm{SE} \\
\text { (kcal/mol) }\end{array}$ & $\begin{array}{c}E a \pm \mathrm{SE} \\
(\mathrm{kcal} / \mathrm{mol})\end{array}$ & $\begin{array}{r}\Delta G^{\#}{ }_{298} \pm \mathrm{SE} \\
(\mathrm{kcal} / \mathrm{mol}) \\
\end{array}$ \\
\hline \multicolumn{6}{|c|}{ Carotenoid fraction } \\
\hline & $\mathrm{N}$ & $-43.44 \pm 0.42 *$ & $15.17 \pm 0.15^{*}$ & $15.93 \pm 0.09 *$ & $28.12 \pm 0.15$ \\
\hline & $\mathrm{D}$ & $-45.22 \pm 1.18$ & $14.55 \pm 0.42$ & $15.34 \pm 0.21$ & $28.02 \pm 0.42$ \\
\hline & $\mathrm{J}$ & $-45.50 \pm 1.69$ & $14.45 \pm 0.61$ & $15.07 \pm 0.22$ & $28.01 \pm 0.61$ \\
\hline & $\mathbf{A}^{e}$ & $-44.72 \pm 1.10$ & $14.72 \pm 0.39$ & $15.45 \pm 0.17$ & $28.05 \pm 0.39$ \\
\hline \multicolumn{6}{|c|}{ Chlorophyll fraction } \\
\hline & $\mathrm{N}$ & $-44.73 \pm 1.47$ & $15.66 \pm 0.53$ & $16.72 \pm 0.21$ & $28.99 \pm 0.53$ \\
\hline & $\mathrm{D}$ & $-48.35 \pm 0.86^{*}$ & $14.34 \pm 0.31 *$ & $15.32 \pm 0.11 *$ & $28.75 \pm 0.31$ \\
\hline & $\mathrm{J}$ & $-45.23 \pm 4.81$ & $15.40 \pm 1.74$ & $16.06 \pm 0.46$ & $28.88 \pm 1.74$ \\
\hline & $\mathbf{A}^{e}$ & $-46.10 \pm 2.38$ & $15.13 \pm 0.86$ & $16.03 \pm 0.26$ & $28.87 \pm 0.86$ \\
\hline
\end{tabular}

${ }^{\mathrm{a}} \Delta \mathrm{S}^{\#}$, activation entropy; $\Delta \mathrm{H}^{\#}$, activation enthalpy; Ea, activation energy, $\Delta \mathrm{G}^{\#}$, Gibbs free energy;

${ }^{b}$ Reactions according to the kinetic mechanism showed in Figure $1 ;{ }^{c} \mathrm{~S}$, Sample codex as in Table 1;

${ }^{d} \mathrm{SE}$, standard error; *Indicates significant differences for a parameter between different samples $(\mathrm{p} \leq 0.05) .{ }^{e} \mathrm{~A}$, average values of the three samples $(\mathrm{N}, \mathrm{D}, \mathrm{J})$. 


\section{FIGURE CAPTIONS}

2 Figure 1. Kinetic mechanisms for thermal decolouration reactions of pigment fractions:

3 chlorophylls and carotenoids.

4 Figure 2. Evolution of concentration-time of chlorophyll pigment fraction ( $O$ ) and 5 carotenoid pigment fraction ( $\square$ ) in VOO (sample $\mathrm{N}$ ) during 42 hours at $120^{\circ} \mathrm{C}$ and 6 corresponding fits ( $\rightarrow$ to a first-order kinetic mathematical model (Eqs. 3-4).

7 Figure 3. A, Arrhenius plot for the decolouration reaction of carotenoid pigment 8 fraction in three samples of VOOs $(\mathrm{N},-\mathrm{a}, \mathrm{D},--\square ; \mathrm{J}, \cdots \diamond)$ ). B, Arrhenius plot for the 9 decolouration reaction of chlorophyll pigment fraction in three samples of VOOs $(\mathrm{N},-\mathrm{O}$

$10 ; \mathrm{D},--\square ; \mathrm{J}, \cdots \diamond \quad$ ). C, Study for isokinetic ratio between Arrhenius plot of decolouration 11 reactions of chlorophylls ( - ) and carotenoids (- $-\square)$ pigment fractions in VOOs 12 (average values of three samples (N, D, J). Confidence intervals (95\%).

13 Figure 4. Graphic representation of $\mathrm{A} H^{\#}$ versus $\mathrm{A} S^{\#}$ by error bars method (Liu \& Guo 14 2001): false compensation effect for the decolouration reactions of the (A) carotenoid 15 pigment fraction and (B) chlorophyll pigment fraction in VOO samples. 


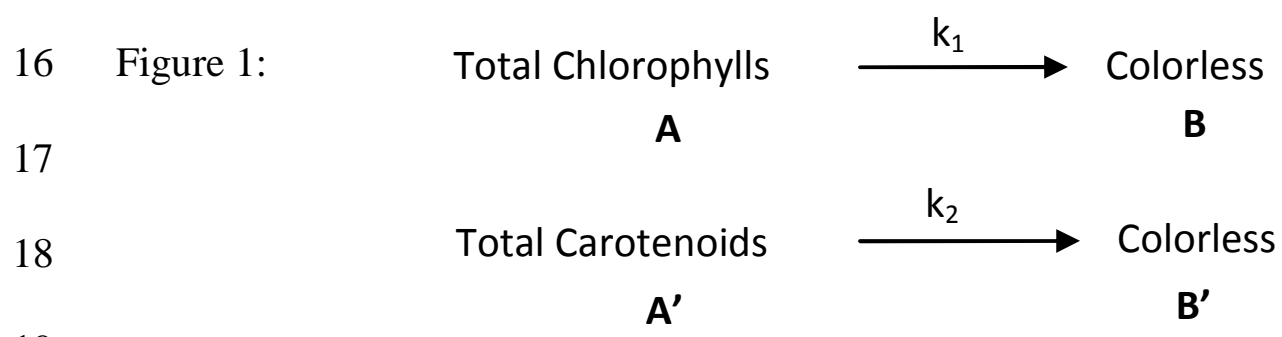

19

20 Figure 2:

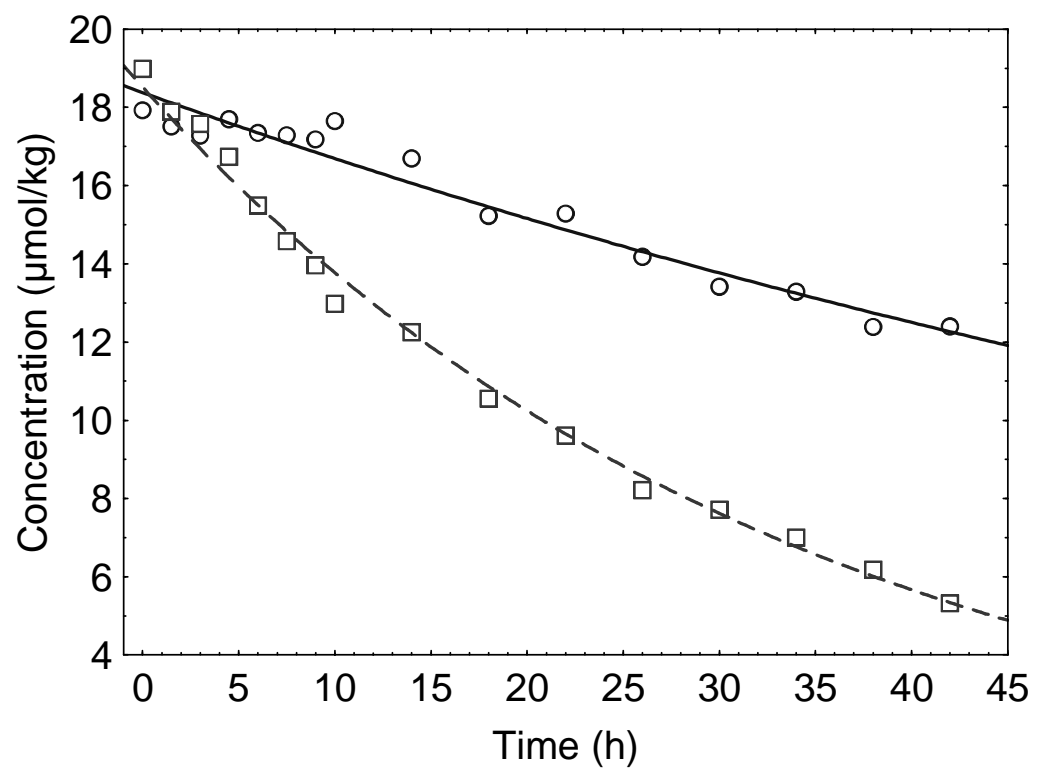

21 
23

24

25

26

27

28

29

30

31

32

33

34

35

36

37

38

39

40

41

42

43

44

45

46

47
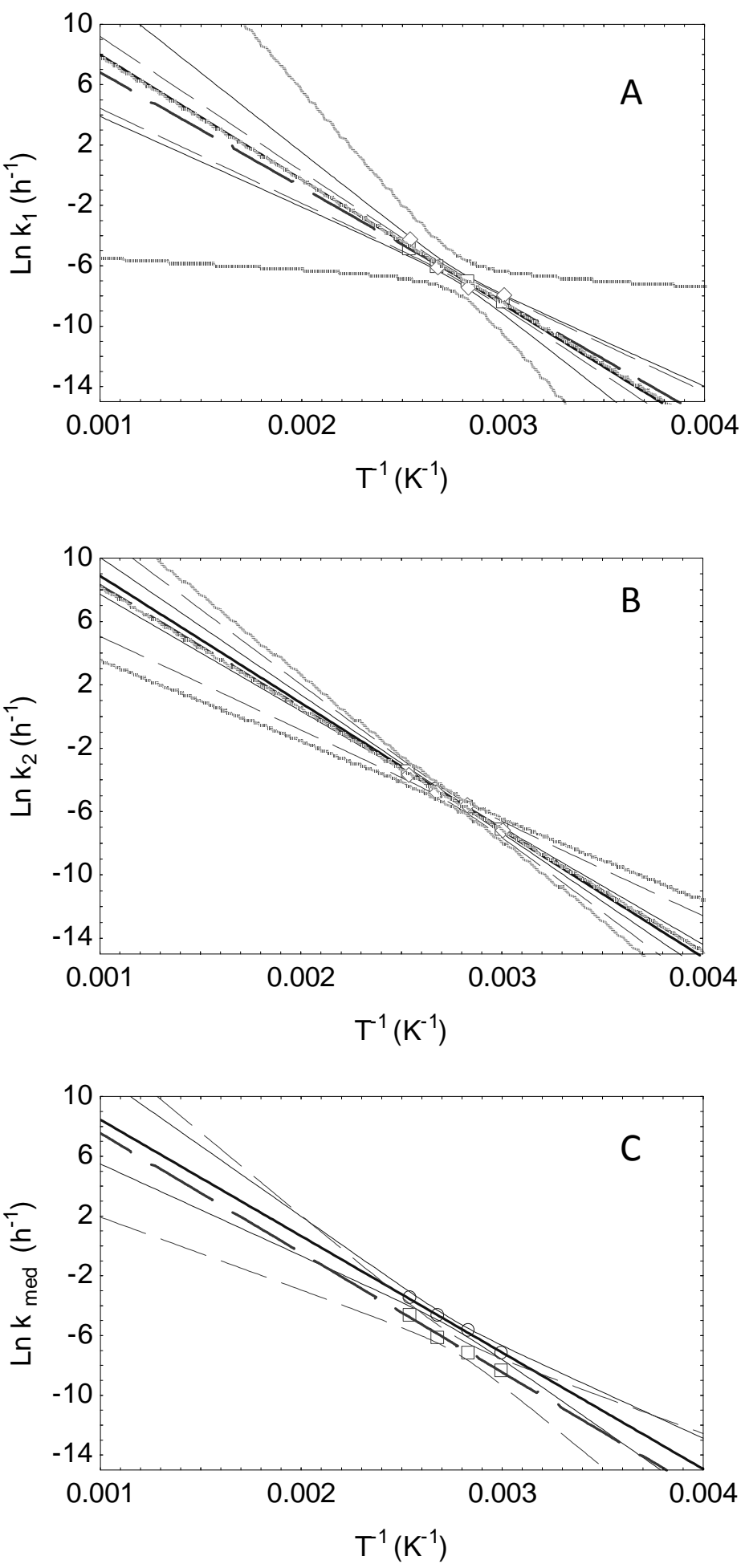
$48 \quad$ Figure 4:
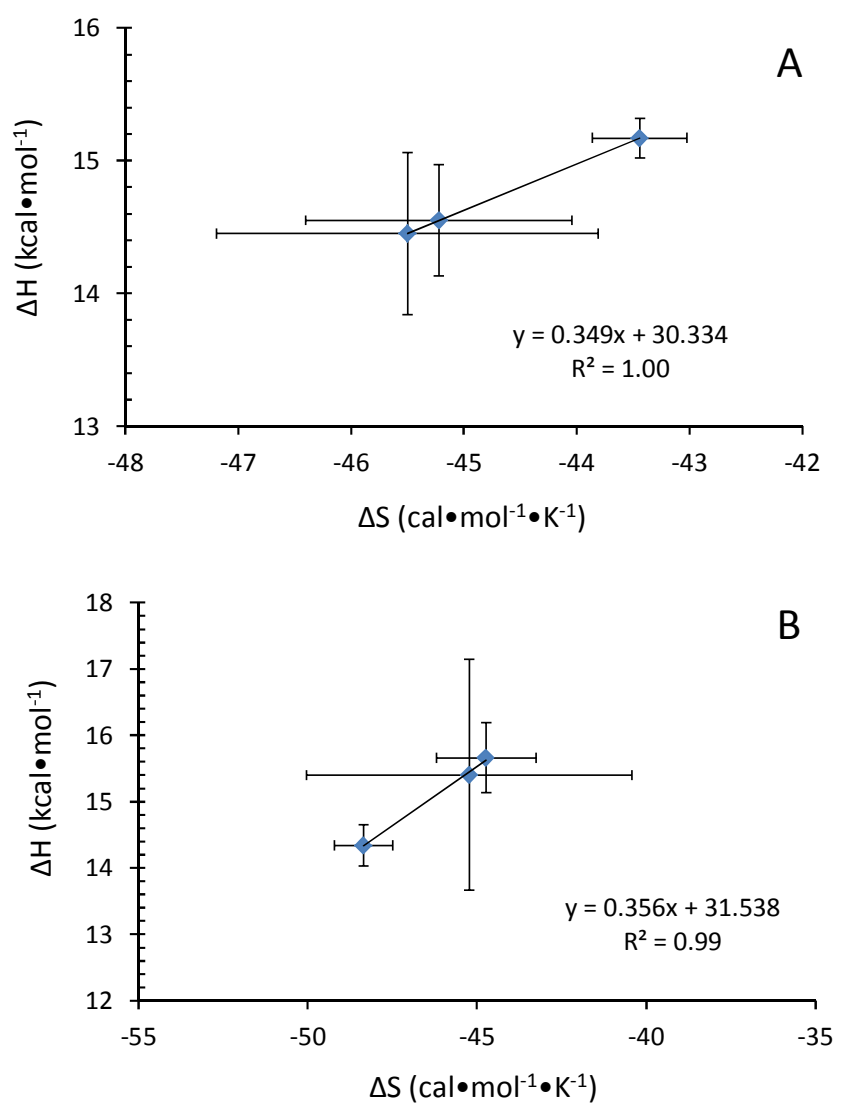

49 